Opisthorchis sinensis, while the Russian troops-with whom our troops have been associated-are subject to 0 . felineus ( $O$. tenuicollis); hence some of the liver troubles of which our returning troops are likely to complain can be diagnosed only by recognizing the eggs of these worms in a microscopic examination of the feces. I do not argue that our medical students should be able to distinguish the millions of insects in the world, or that they should make a collection of beetles instead of bones, but in view of the demonstration that certain species of mosquitoes, belonging to the genus Anopheles, transmit malaria, other mosquitoes belonging to the genus Culex transmit filarial elephantiasis, and Culex fasciatus is now alleged to transmit yellow fever, it does not appear extreme to advance the view that physicians should know something about the breeding habits of these insects. It is not the intention to try to introduce abstract zoologic work into medical colleges, but when we consider how often patients are treated for worms when they have none, and how often they have some which for a long time escape diagnosis it seems justifiable to suggest that if medical students were taught how to distinguish the eggs of various orders by a microscopic examination of the feces, the liability to error in diagnosis would be diminished.

The time will probably never come when our professors of practice will think it best not to discuss malaria, dysentery, trichinosis, and other diseases associated with animal parasites, and we should in fact be opposed to having the clinical side of these maladies turned over entirely to zoologists. Still, the subject of practice is so broad that no one man-not even an Osler-can hope to keep up to date in the entire literature bearing on all its phases. By common consent the chair of practice surrenders the phytoparasites to a botanist or a bacteriologist, and my contention is that if our medical schools are to keep abreast of the times in practice, pathology, and hygiene, the subject of animal parasitism should be treated in a special course, by a special man, preferably by a professional zoologist, if the services of one who has worked in the groups in question can be obtained, otherwise by a physician who has had a general zoologic and special helminthologic training.

Such a course as outlined above should be allotted between twenty and thirty lectures and at least three laboratory exercises, although under pressure the field may be covered-though with less satisfaction to the instructor-in about eighteen lectures.

\section{ANTIPNEUMOCOCCIC SERUM TREATMENT OF PNEUMONIA, WITH REPORT OF CASES.*}

G. E. TYLER, M.D.

Secretary Colorado State Board of Health; Adjunct Professor of Medicine, Gross Medical College; Visiting Physiclan to St. Anthony's Hospital and to the Arapahoe County Hospital. DENVER, COLO.

DISCOVERY.

In 1888 Netter rendered mice and rabbits immune to pneumonia by injecting them with a fluid prepared from the dried spleen of infected animals. Later he used an old pneumococcus pleuritic exudate, and still later the sputum of a pneumonia patient after the crisis.

* Read before the Denver and Arapahoe Medical Soclety, Feb. $12,1901$.
Foa was able to produce, in animals, an immunity lasting several months, by injecting a serum made by a precipitation of a bouillon culture of the pneumococcus with ammonium sulphate and repeated filtration. His method was to inject the filtrate intravenously into rabbits for three or four days. Later he made an extract of the muscles and viscera of a rabbit, dead of pneumonia; precipitated it in the same way, used it in the same manner, and was able to produce the same immunity; though a similar extract from a healthy rabbit produced no effect.

Klemperer Brothers experimented with a pneumococcus pleuritic exudate which was demonstrated, by cultural methods, to contain no living organisms. They injected two rabbits with 20 c.c. each, and fourteen days later they inoculated both these animals with a virulent culture of the pneumococcus. Both survived, though the control animal died. They also succeeded in rendering dogs immune. Later they demonstrated the curative properties of the serum of animals rendered immune to pneumococcus infection.

Pane and De Renzi inoculated animals with the pneumococcus, and from them obtained a powerful antipneumonic serum. They submitted their results to the Medical and Surgical Academy of Naples, and this body, after repeated tests, declared the serum to be of great value. The harmless character of the serum was also established by the injection into men of 200 c.c. in twenty-four hours, without the experience of any inconvenience. The Klemperers advanced the theory that during the course of pneumonia there is developed in the blood a poisonous albumin called pneumotoxin, and that the system elaborates an antipneumotoxin, this latter substance causing the crisis. They were able to demonstrate the presence of the antipneumotoxin in the blood of pneumonia patients after the crisis; and they also succeeded in curing the disease in animals by the use of antipneumotoxin.

\section{NATURE.}

Vaughan considers that the action of the serum is antimicrobic and not antitoxic. McFarland says the nature of the serum is uncertain; it may be antitoxic or antimicrobic, probably antimicrobic. Lambert considers that it may be bacteriolytic in its action.

A. H. Smith says whether the antitoxin is the product of the pneumococci or is simply the result of changes going on in the leucocytes, preparatory to their disintegration, is not yet determined. Smith also cites an observation of Pinna that the pus obtained by injecting turpentine into the cellular tissue of a man, the pus being proved absolutely sterile, had the power, when injected into rabbits, of rendering them immune to inoculations with pus containing pneumococci, though the unprotected animals inoculated in the same manner died of pneumococcus septicemia within thirty-six hours. Smith adds: "It would appear from this that the pus itself, apart from any microbic action, possesses antitoxic properties."

Tizzoni claims that the serum is not only protective against the pneumococcus, but that it protects against reaction to small fatal doses of the tetanus bacillus, while on the other hand the tetanus serum renders the animal less susceptible to pneumococcus infection, and McFarland cites an instance where it protected against the streptococcus.

It may safely be concluded that antipneumotoxin is not a bactericide. The pneumococcus is not killed by contact with it. Instead, the organism multiplies, de- 
velops, and retains its virulence under these conditions. On the other hand, the antipneumococcic serum, when injected into animals, prevents the development of symptoms due to the formation of pneumotoxin. If pneumotoxin alone be injected into a rabbit, it causes rise of temperature, toxemia, and death from general pneumococcus septicemia; but if the pneumotoxin be mixed with antipneumococcic serum and injected, no rise of temperature nor other symptom develops. It is probable, therefore, that the serum does not prevent the development of pneumotoxin, but that it either renders the pneumotoxin inert through chemical processes or else it counteracts its effects.

\section{PREPARATION.}

Some experimenters have used a glycerin extract of the muscles and viscera of immune animals. Others have obtained the serum direct from different animals. That the different methods of preparation influence the result to some extent is proved by the observation of Lara, who stated that the serum from dogs caused nervous excitement, while that from rabbits produced general agitation and a temporary aggravation of the disease. It is therefore important to determine what method is used in the preparation of the serum employed, in order to properly interpret the effects reported.

Washbourn used essentially the same method as that employed in producing diphtheria antitoxin. A pony was inoculated with cultures of the pneumococcus, for three months. At the end of this time the animal was found to possess marked immunity. In order to increase the virulence of the pneumococcus Washbourn devised a special method of culture and kept the culture in an incubator at $37.5 \mathrm{C}$. for sixty-six days, and he states that the serum may also be accurately standardized.

MeFarland states that the same process applies to the manufacture of the antipneumococcic serum as applies to the manufacture of diphtheria antitoxin, except that it is necessary to cultivate the pneumococcus by a special method. He first injects virulent bouillon cultures which have been killed by heating to $60 \mathrm{C}$. for one hour. After the horse has stood injections of increasing doses, living cultures are given in increasing doses until the horse no longer reacts. The protective character of the serum is demonstrated against living organisms injected into rabbits. Then the horse is bled, the serum is treated with trikresol and in this shape it is put upon the market.

\section{REPORT OF CASES.}

Lara reported the results of 10 cases treated prior to Dec. 2,$1892 ; 5$ were cases of double pneumonia, 5 single; 8 were young persons, 2 were advanced in years; 6 were robust, 4 debilitated. He employed different sera; in some cases using that from immunized rabbits; in other cases from dogs, and in still others the glycerin extract of the viscera; no local reaction followed any injection. The rate of the pulse was unchanged, but its character was altered. There was no immediate change in respiration, but after a time it became slower. In every case the crisis occurred from the third to the fifth day; convalescence was rapid and complete and the complications were rare and of little gravity. In all but three cases reduction of temperature followed the injection. Lara was encouraged by the results.

Oct. 31, 1896, De Renzi reported 16 cases. 2 of whom were treated in 1894-95, both recovering. During 189596,12 recovered and 2 terminated fatally. Feb. $27,189 \%$, Washbourn reported 1 case of his own who recovered and 1 case of Pye-Smith, also with recovery. April 18,
$189 \%$, Spurrell reported 1, the patient dying. May 22, 1897 , A. Cooke reported 2 cases, both of whom recovered.

On the same day Harnett reported 1 in an alcoholic, terminating in recovery. Dec. 25,1897 , Washbourn reported 6 cases, all terminating in recovery. Jan. 30, 1898, Pane reported 9, of whom 8 recovered and 1 died. He stated that in the 8 patients who recovered, rapid improvement followed the use of the serum, and there were no ill effects. During 1898 De Renzi reported 10 additional cases, all of whom recovered. Feb. 15, 1898, Weisbecker reported 21 with 19 recoveries and 2 deaths. $\mathrm{He}$ stated that the results were most striking, there being a notable change for the better in the patient's general condition. Of the 2 fatal cases, 1 was due to emphysema and the other patient was $\% 8$ years old. May $\%, 1898$, Fanoni reported 1 case treated with De Renzi's turkey serum, with recovery. In October, 1898, Marsalongo and Franchini reported 10 cases with 7 recoveries and 3 deaths; the three fatal cases being alcoholic subjects. Aug. 26, 1899, Fanoni reported 5, with 4 recoveries and 1 death. The fatal case was a female patient, and her death should not really be attributed to pneumonia, as she was in full convalescence when pericarditis or endocarditis developed, (ausing her death. In March, 1890, Canby reported 4 cases, all of whom recovered, 1 being his own ease, 1 a patient of Dr. Frey, and 2 patients of Dr. Everhart. April 14, 1900, Lambert reported 12 cases of his own, with 9 recoveries and 3 deaths; he also quotes Bozzolo as having treated 5 , with 4 recoveries and 1 death. lambert's experience with Pane's serum was unfavorable, but he states that this was probably due to the fact that the serum was old; he then substituted serum from horses and had better results. He states that the rerum does not seem to have any effect on the process in the lungs nor to hasten the crisis, but that in certain instances it does prevent the development of a pneumococcus septicemia; and in these cases it may save life. Sept. 8, 1900, J. C. Wilson reported 18 patients treated at the German Hospital, Philadelphia, the usual treatment at the hospital being given simultaneously: 2 were women and 16 men; the youngest was 15 , the eldest 48; all were working people and most of them were occupied up to the time of the attack. Of the 18 patients, 14 recovered and 4 died. Wilson used small doses at first, but later increased the amount given. $\mathrm{He}$ calls attention to the great increase of leucocytes following the injection of the serum. In the discussion of this case A. O. J. Kelly reported 1 of double pneumonia treated with the serum terminating fatally; but he states that the case was considered hopeless when the serum was begun, and that the supply of serum gave out some time before death ensued. He also states that marked increase of leucocytes followed each injection. McFarland reports, during the year 1900, among others, 1 patient treated by Rochester, with recovery.

The cases which I report were all treated at the Arapahoe County Hospital, during the fall of 1900. Other treatment was employed simultaneously, consisting of ice-pack to the chest, strychnia, alcohol, and digitalis as needed and oxygen in desperate cases.

CASE 1.-R. C., a white labor: 1,45 years old, was admitted Sept. 26, 1900, with acute alcoholism and pneumonia of the right upper and middle lobes, it being the eighth day of his illness. He had been without medical attention up to the time of his admission. The affected lobes were found consolidated. On September 27, the ninth day of the disease, serum treatment was begun, 20 c.c. being given subcutaneously every eight hours. 
Unfortunately the supply of the serum gave out, there being no more in Denver at the time, so that he had but six doses, the last being administered the morning of September 29; the patient died the morning of September 30 . Later arrangements were made for a systematic test of the serum, and it was administered to every pneumonia patient admitted to my service, from October 25 to November 25 , regardless of the general condition of the patient or the stage of the disease; 20 c.c. of Mulford's serum being given subcutaneously every six hours.

CASE 2.-.J. C., a white teamster, aged 39. was admitted Oct. 25. 1900. the second day of the disease. His family his-

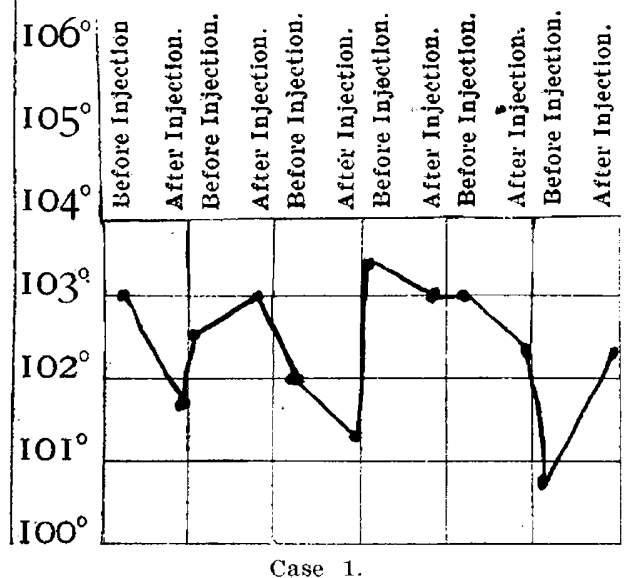

tory was negative, and he gave a personal history of pulmonary hemorrhages in 1883. The right upper lobe was consolidated. Serum was begun October 26 , the third day of the disease. He received eleven doses of 20 c.c. each at intervals of six hours. The crisis occurred the fifth day of the disease and convalescence was rapid.

CASE 3.-F., an insane man about 50 years old, had a chill and severe sharp pains in the right chest during the night of November 3. He was transferred to my service and I saw him the morning of November 4. There was slight duiness and diminished respiratory sounds over the lower right lobe.

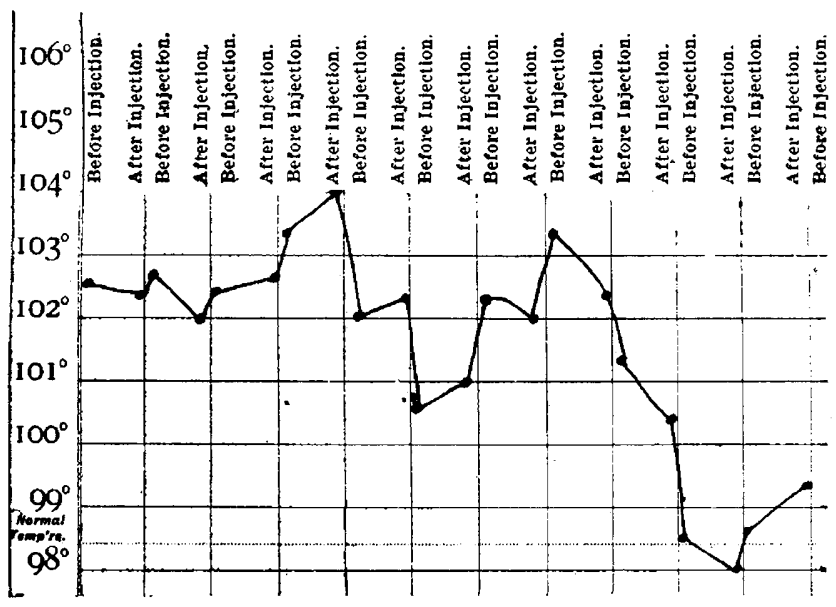

Case 2 .

The next day there was increased dulness with bronchial breathing. The serum was begun during the first twentyfour hours of his illness, and he had six doses of 20 c.c. each The crisis occurred the third day and convalescence was rapid.

CASE 4.-M. St. C., a negro woman, 19 years of age, a morphin habitue, was admitted November 11. Because of the un reliable character of her testimony, no history could be obtained. I first saw her on November 12. Both lower lobes were consolidated, with flatness, tubular breathing and exquisite pectoriloquy. She had fourteen doses of 20 c.c. each, at intervals of six hours, this treatment being begun the day of her admission. The crisis occurred the fourth day she was in the hospital, though it was not typical, and there were some fluctuations of temperature thereafter. She made a good recovery.

CASE 5.-T. G., a white woman, 18 years of age, with constitutional syphilis, was admitted November 19 , the fifth day of the disease. The right lower and middle lobes were consolidated. The serum was begin the fifth day of the affection

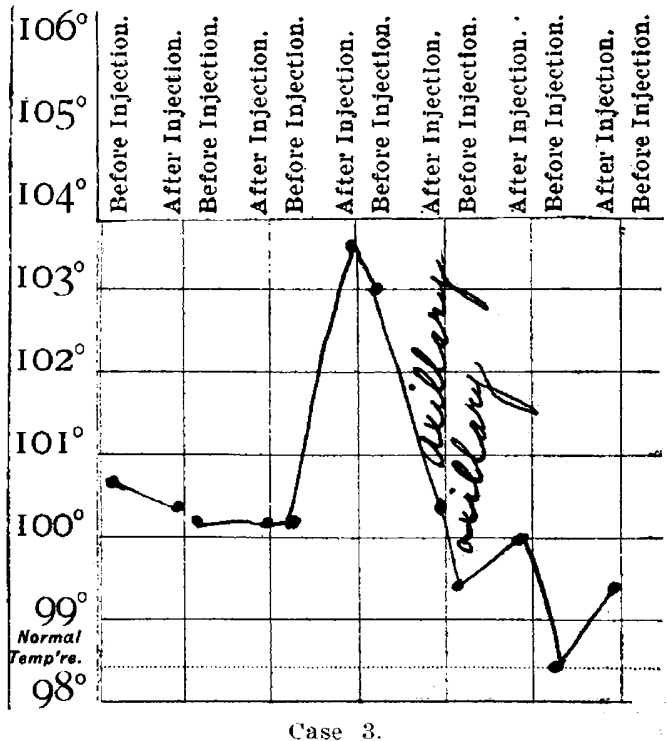

and she had twenty doses. No crisis occurred. A septic ar. thritis developed, affecting the left elbow, and she was tranferred to the surgical ward. At this time she had practically recovered from her pneumonia, but I saw her about six weeklater and discovered evidence of softening of the right lung.

CASE 6.-J. B., a white male cook, aged 22, was admitted November 21, the 5 th day of the disease. The lower left lobe was consolidated. Serum was begun at once and he received eight doses of 20 c.c. each. The erisis occurred the sixth day of the disease and convalescence was speedy.

The appended charts show the sffects of serum on the temperature. Aside from any objective symptoms there was lessening of dyspnea, and often the patient iropped into a comfortable sleep after the injection.

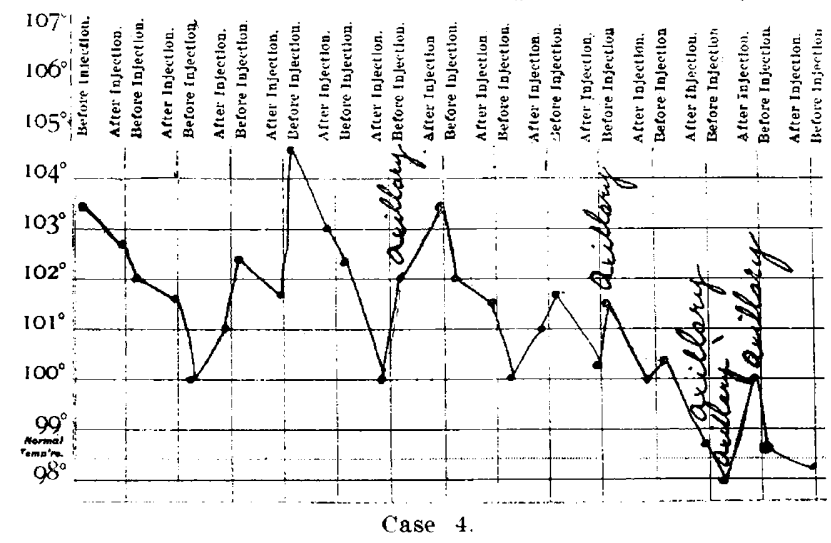

In no case did a general toxemia develop. In one case (No. 5) there was considerable local irritation at the seat of injection.

It will thus be seen that I have collected, including my own, 141 cases treated with antipneumonic serum of some sort, with 121 recoveries and 20 deaths, a mortality of 14.18 per cent. In those cases where I have had access to the original report, I have especially studied the fatal cases. Weisbecker had 2 deaths, one being emphysematous and the other 78 years old. Marsalongo and Franchini had 3 deaths, all alcoholics. 
Fanoni had 1 death, but it was from cardiac disease after convalescence was fully established. Of Lambert's fatal cases, 2 were alcoholics. Of Wilson's, 1 died on the third day, the entire right lung being solid; 1 had been ill with la grippe for two weeks; 1 was an alcoholic, the left lung being entirely solid, and death occurred on the fifth day; the other patient weighed 200 pounds and was addicted to malt liquors. Kelly had 1 death, but in! an alcoholic considered hopeless before serum was

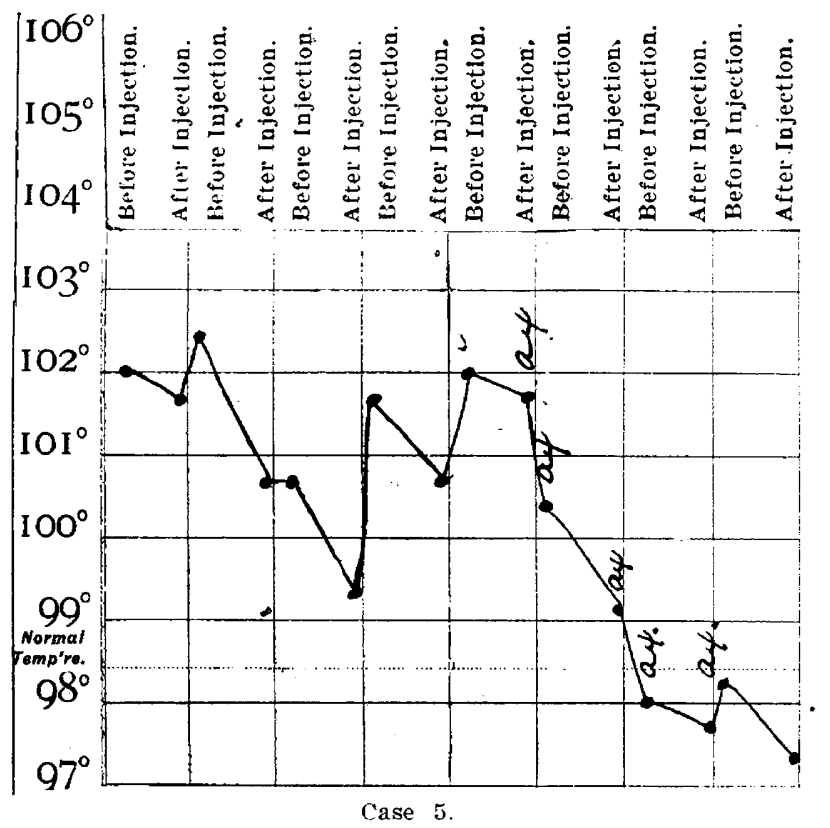

administered, and the supply of serum gave out before death. My one death was in a patient with acute alcoholism, no treatment at all being instituted until the eighth day.

In attempting to estimate the effects of the serum, most, if not all the cases just mentioned ought really to be excluded. If these be excluded, we have 127 cases, roborative evidence of the value of the serum. Unfortunately, in my case, no blood counts were made.

I have found no statement of the effects of the serum on the chlorids in the urine. It is to be hoped that subsequent observers will study this also.

The thing which most impressed me during my observation was the complete absence of toxemic symptoms. If it be true, as is claimed, that the pneumococcus enters REPORT OF CASES TREATED WITH ANTIPNEUMONIC SERUM.

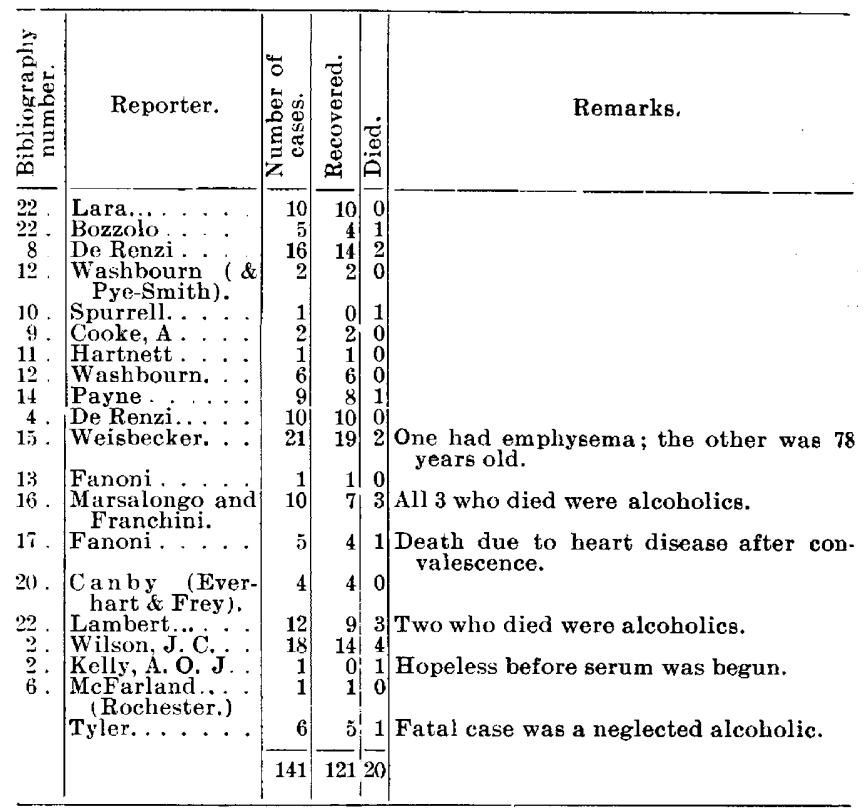

the blood from about the third day to the fifth day of the disease, and that prior to that time there are no preumococci in the blood, and if it be true also that the advent of the organisms into the blood marks the beginning of the toxemia or septicemia, these facts furnish a rational explanation of the effects of the serum when begun early.

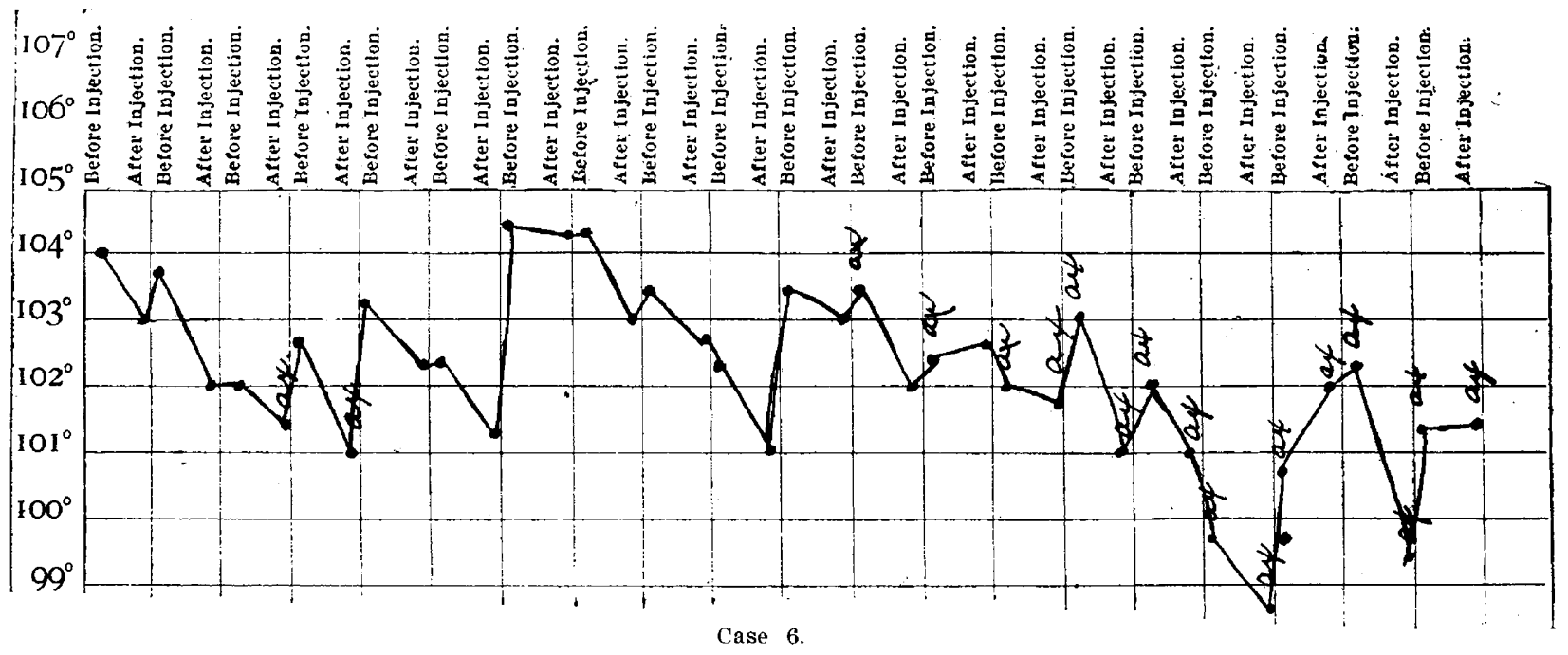

11iti 6 deaths, a mortality of 4.7 per cent. In view of the different sera used, especially when the difficulty of producing and keeping a good antipneumonic serum is considered, this seems to me an excellent showing.

Wilson, Kelly and others have called attention to the increase of leucocytes following injections of the serum. As absence of leucocytes in pneumonia is considered of grave prognostic import this is good cor-
Osler mentions toxemia as the important prognostie factor, and it is one of the most, if not the most. important item in determining the outcome. It is my opinion that if fresh serum in large quantities be given before the advent of the pneumococcus into the blood, it will prevent the development of toxic symptoms. This also' coincides with the results of animal experimentation. Animals inoculated with the pneumococcus do not die 
of pneumonia, but of pneumococcus septicemia; and as is well known, the results of animal experimentation are extremely encouraging.

It is exceedingly doubtful whether antipneumonic serum has any effect on the condition of the affected lung. The exudate is extracirculatory; the vascular supply being cut off. It is therefore almost inconceivable that the serum should have any effect on it, except possibly to prevent the involvement of new areas. But if we have a serum which prevents and combats toxemia, as I believe we have, that is a great advance.

Several problems of much importance yet remain to be solved. The standardization of antipneumonic serum, so essential to accurate dosage, the easy cultivation of the pneumococcus in such a way as to prevent loss of virulence, the concentration of the serum to permit smaller dosage and the reduction in cost of production so essential to its popular use, all these are yet in the future.

DIscrissron.

Dr. J. N. HALL-I saw all of the cases and in addition have seen one or two others, notably one with Dr. Holmes, which I report with his permission, a case where a pneumonia supervened upon an old standing phthisis, and in that case the result was fatal. It was due, however, rather to the phthisis than to the pneumonia. I have not as yet been convinced of there being any great therapeutic effect in this serum, still $I$ think it is a lead which is well worth following. I am rather prejudiced against the general proposition that the pneumococcic serum will be of much value, because of some preconceived notions, and yet I am open to conviction. It is well known that pneumonia is not a disease uniformly due to the same organism. Something like four-fifths of the cases are due to the pneumococcus, while in the remaining Fraenkel's bacillus, the streptococcus and various other organisms are found. In very many of the cases of la grippe pneumonia, as is well known, a mixed infection is present. We are in much the same position as regards pneumonia as we were in regard to diphtheria before the bacteriologic differentiation of the disease. In those days we called all cases of false membrane in the throat diphtheria, whereas we now know that many of these ar: due to a streptococcus infection. It is only in the diphtheria pure and simple that the diphtheria antitoxin is of much value. If we had the means of knowing absolutely the bacteriologic diagnosis in our cases of pneumonia, we should have a betrer opportunity for estimating the true value of the pneumocoecic: serum. As in the use of streptococcic serum in puerperal fever, it is essential that we should know the exact organism causing the symptoms before we can hope to form just estimate of the value of the remedy.

I have seen within six days six cases of diphtheria and three of streptococcic sore throat. all having much the same clinical appearance. Before the days of the use of the diphtheria serum, if such a thing were possible as that the remedy could have been injected, we should have been completely mystified because of the good effect which it had on certain of these cases, and the absence of any effect in others. Therefore, as I say, I do not feel that we can very justly estimate the value of this serum, because we can not tell how many out of the 141. cases reported by Dr. Tyler were die to a pure pneumococcic germ. It is perfectly possible that all of these that recovered were due to that. In that case we should have a very high estimate of the value of the serum, and we should be all the more diligently led to study to find a serum which we may use for the other cases.

Furthermore, we should bear in mind that in pneumonia it is more difficult to give an exact prognosis than in almost any other disease. We occasionally see patients who, by all rules of prognosis, ought to die, and yet they recover. In the report which I made a few years ago before this society, of all the cases of acute lobar pneumonia which $I$ had seen in private practice, every patient over 70 years of age, much to my surprise, had recovered. A week ago I saw, with Dr. Hawkins, a case in a young woman so desperately ill that we both agretd that her prognosis was entirely hopeless. She had not been treated with the vigorous stimulation which we commonly use in these cases, yet when it was adopted she promptly recovered, being out of danger in forty-eight hours. Where such cases as these quoted may be seen, the difficulty of prognosis is evident. Finaliy, there is sufficient encouragement in the use of this serum to lead us to strive more diligently than ever to find a treatment of the disease which, with more accurate bacteriologic diagnosis, shall give us such results as we have already seen in the treatment of diphtheria.

DR. A. M. Holmes-Dr. Tyler's subject is an important one. I have had very little experience with the antipneumococcic serum, having used it in but one case. The case referred to was by no means a favorable one for a test. For several years the patient had been afflicted with phthisis. Pneumonia developed after exposure and had been in progress for several days when I first saw him. Dr. Hall was kind enough to see the patient with me. As a last resort we decided to make use of the antipneumococcic serum, and we had an opportunity to carefully observe the effects. I should like to report a few points, many of which closely resemble those reported by Dr. Tyler. Other means of treatment were used in addition to the serum, oxygen being administered almost constantly. Wild delirium was present, accompanied by rapid pulse and very little fever. We injected 20 c.c. of antipneumococcic serum at intervals of four to eight hours. We observed improvement in the pulse, in the respiration, in the delirium and the restfulness of the patient soon after giving each injection, but the improvement was only of short duration; the case terminated fatally at the end of one week after we began the serum. A bacteriologic examination of the sputum was made when we first saw the patient; numerous pneumococci, tubercle bacilli and other germs were found. Several days after we had been giving the serum another examination of the sputum was made and the pneumococci were not found, but the tubercle bacilli were present. The blood examination revealed a slight in crease in leucocytosis, which soon diminished. There were no bad effects that could be ascribed to the serum. The patient himself frequently remarked that he felt better after receiving the injections. When administering antipneumococcic serum it should be fresh, be commenced early in the course of the disease, and be given in large doses and at short intervals. From my limited experience $I$ am of the opinion that antipneumococcic serum possesses sufficient worth to justify further use.

BIBLIOGRAPHY.

1. Solomon, L. L.: Materia Medica, Pharmacy and Therapeutics; Jour. AM. Med. Assn., 1900, xxxv, 35, pp. 333-35.

2. Wilson, J. C.: Serumtherapy in Croupous Pneumonia; Ibid., pp. 595-600.

3. Rosenthal, Edwin: Treat. of Pneumonia with Antipneumococcic Serum; Med. News, 1900, Ixxvii, pp. 851-52.

4. Smith, W. H. : Serumtherapy in Pneumonia; Boston Med. and Surg. Jour., Oct. 4, 1900, exliii, pp. 340-42.

5. Carnot, $P_{\text {., }}$ and Fournier, L.: Recherches sur le pneumocoque et ses toxins; Arch. méd. expérim. et d'anat. pathol., I. S., v. xii, 1900 , pp. $357-78$.

6. McFarland: Serumtherapy in Croupous Pneumonia; Boston Med. and Surg. Jour., 1900, cxlli, p. 639.

7. Gould's Year-book, 1898

8. De Renzi : Il Policlinico, Oct. 31, 1896.

9. Cooke, A.: British Med. Jour., 1897, pp. 1278-79

10. Spurrell, C.: A Case of Pneumonla Treated with Antipneumococcic Serum ; Ibid., April 17, 1897, p. 973.

11. Harnett, C. J.: A Severe Case of Pneumonia in an Alcoholic Subject Treated with Antipneumococcic Serum; Recovery; Ibid., May 22 , 1897 , pp. 1279-80.

12. Washbourn, J. W.: Antipneumococcic Serum; Ibid., Feb. 27, 1897 , p. 510 ; Dec. $25,1897$.

13. Fanoni, Antonio: The New Treatment of Pneumonia with De Renzi's Serum ; N. Y. Med. Jour., May 7, 1898, Ixviii, pp. 646-48. 14. Pane: Gaz. degli Osped. e delle Clin., Jan. 30, 1898.

15. Weisbecker: Die Serumtherapy gegen Pneumonia; Münch. Med. Woch., Feb., 15, 1898, pp. 202, 238.

16. Marsalongo and Franchini : Riforma medica, No. 31, 1898.

17. Fanoni: Report of Six Cases of Pneumonia Treated with Antipneumococcic serum ; N. Y. Med. Jour., Aug. 26, 1899, lxx, pp. 302-306.

18. McFarland, Jos., and Lincoln, C. W. : A Preliminary Note on Antipneumococcus Serum; JoUr., Am. Med. AssN., Dec. 16, 1899, Xxxili, pp. 1534-35.

19. Fanont: Antipneumonic Serum; Med. Record, March 10, 1900 , p. 431 .

20. Canby C. B.: A Case of Pneumonia Treated with Antipneumotoxin ; Maryland Med. Jour., March, 1900, xliil, pp. 113-119. 
21. Klemperer, G., and F.: Versuche über Immunisirung u. Heilung beider Pneumokokkeninfection; Berliner klin. Woch., 1891, Aug. 24 and 31, pp. 833 and 869 .

22. Lambert, Alex.: Use of Antipneumococcic Serum; Jour. Am. MED. Ass.., April 14, 1900, xxxiv, pp. 900-902.

23. Eichhorst, Herm. : Behandiung der fibrinosen Lungenentzündung ; Therap. Monatshefte, l'eb., 1900, pp. 63-66.

24. Mo. Cyclop. of Pract. Med., xiv, July, 1900, p. 252-4.

25. Progressive Med., Sept., 1899, pp. 49-51.

26. Ibid., p. 19. 127.

28. N. Y. Med. Jour., May 7,1898 , pp. 646 and 647 .

29. Med. Record, May 14, 1898, p. 714 .

30. Gaz. d. Osp. e delle Clin., March 6, 1898

31. Gould's Year-book, 1901, p. 497.

\section{HOW TO TREAT MUSCULAR AND JOINT SPRAINS OF RAILWAY EMPLOYEES.* HALDOR SNEVE, M.D. \\ CHIEF SURGEON, CHICAGO GREAT WESTERN R. R. ST. PAUL, MINN.}

Joint and muscular sprains differ, so far as I know, not the slightest from the same affections in other occupations, but the same justification that obtains in calling railway surgery a special branch of surgery will allow of the use of the title of this paper. Sprain of some sort or another is a very common accident arnong railway employees. This is perhaps due to the fact that so many of them, in the discharge of their duties, are forced to run backward and forward, work on machinery in constrained positions, do heavy lifting, and are exposed to falls from heights. In order to form an idea of how frequently such accidents affect railway employees, I have prepared a table of the sprains and strains of all kinds, reported as such to my office, occurring on the lines of the Chicago Great Western for the year 1899:

SPRAINS AND STRAINS OF CHICAGO GREAT WESTERN R. R. EMPLOYEES, 1899.

Firemen.

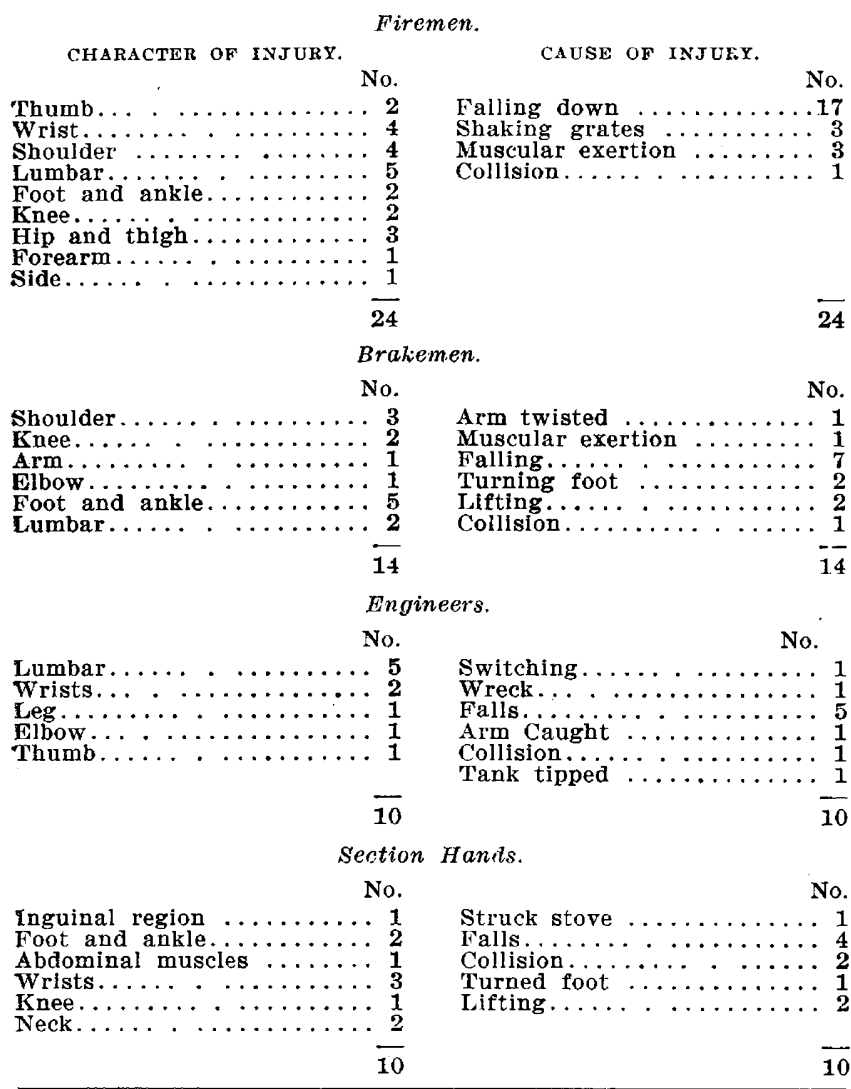

* Read at the annual meeting of the Academy of Railway Sur geons, held in St. Paul, Minn., Sept. 5 and $6,1900$.

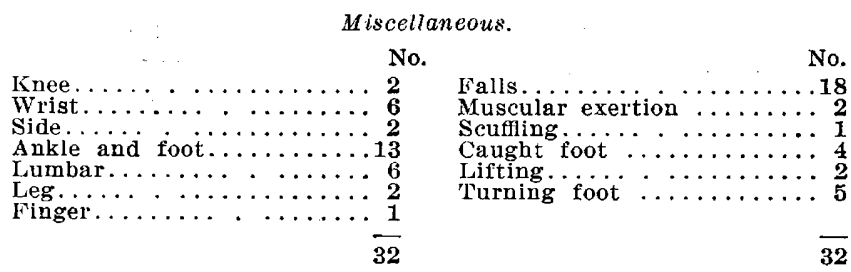

It will be seen from the table that, as far as occupation is concerned, the greatest number injured, strangely enough, were firemen, to the number of 24 .

We would have expected a priori that the number of sprains would have been greatest in the brakemen, who are continually climbing over cars and running backward and forward along the train, but the number of these so injured was only 14. Next were engineers and section hands, 10 each, and finally all other occupations, switchmen. machinists, wipers, carpenters, etc., to the number of 32 , making a total of 90 cases reported to my office as sprains or strains, out of a total of 622 accidents for the year 1899 . The percentage of sprains and strains to the total is $\mathbf{1 4 . 4 5}$.

The character of injury in all these cases has been sprains or strains of fingers, wrist-joints, shoulderjoints, foot and ankle, knee, hip and thigh, arm, back and side. By far the largest number of sprains reported were of the ankle and foot. 22 cases out of 90 . Wrists were sprained 15 times. In all the cases of strains, by far the greatest number were of the back, or, as I have tabulated it, of the lumbar region, a total of 18 cases. It appears that engineers hurt their backs, brakemen their ankles, while the firemen sprain backs, wrists and shoulders indifferently.

The cause of injury shows a preponderating number due to slipping and falling, resulting in injuries to the wrists and ankles especially. The total number of cases due to falling is 51. Various sorts of muscular strains resulting from muscular exertion were present in 9 cases.

The percentage of sprains and strains in a total of 622 cases being 14.45 , these are therefore frequent accidents among railway employees, and six years of experience in railroad work leads me to believe that these are precisely the injuries which lay up the employees the greatest length of time, and the object of this paper is to show how the time of recovery can be shortened, in my opinion at least 50 per cent.

What do we mean by sprain? The definition of Dr. Douglas Graham is a very good one: "A sprain is a sudden partial displacement of two joint surfaces followed by immediate replacement." A strain is a stretching of the tissues beyond their normal limits, resulting in rupture of some of the tissue elements. These strains may affect any of the tissues, but do not, in my opinion, ever occur in ligaments.

Dr. P. S. Conner, Cincinnati, teaches that ligaments are made up of white fibrous tissue which is absolutely inelastic, and therefore can not stretch; at the same time it is so strong that it is easier to pull it from its attachments in bone or muscle-tendon-than to rupture it. A writer in Gerrish's Anatomy says that a little reflection will teach us that if tendon could stretch then our muscular efforts would be wasted on the elasticity of the medium between muscle and bone. Morris' Anatomy also teaches that white fibrous tissue is incapable of stretching. I mention this particularly because the term "stretching of the ligaments," especially as applied to the ankle-joint, is used so frequently and so loosely. In a very few instances postmortems after 